\section{Imaginative reflections}

The Lives of a Cell: Notes of a Biology Watcher. By Lewis Thomas. Pp. 153. (Viking: New York; Garnstone; Lon-

For once the publisher's blurb is At first glance this is not apparent. The book is a collection of essays, 29 of them, each no more than about five pages long, reprinted from issues of the New England Journal of Medicine from 1971 to 1973. The author is a distinguished clinician, but the essays are not about medicine (except incidentally); most of them are imaginative reflections about societies of insects and men. The best way to convey the flavour of Thomas' book is to understanding at the behaviour of some simple organisms-in which he includes mitochondria, chloroplasts, bacteria, ants and termites-and his wonder leads him to speculate about the behaviour of man. This theme could be a recipe for sentimental teleologya sort of latter-day Maeterlinck. But Dr Thomas is too good a biologist to fall into that trap. He knows that to impute even the rudiments of human intelligence to insect communities is nonsense; social insects have no choice but to build nests or hives, to store food, to cultivate fungi, to live in symbiosis with other creatures; all under inflexible genetic compulsion. But (he asks) are there not also examples of genetically coded behaviour in men and communities of men? And it is his speculations about this question which make this book such delightful reading. I use the word 'delightful' deliberately; for the book contains few facts which are not familiar to biologists, and it does not weave these facts into logic, it spins speculations out of them. The essays are little flights of imagination, written with charm and wit. But they are anything but trivial. In practically every essay something familiar is suddenly put into a fresh light, and it looks quite different; and this, of course, is precisely how creative science is achieved. Dr Thomas has a flair for 'thinking otherwise' about familiar things.

For example, he includes mitochondria as 'organisms', for one of his themes is the prevalence of symbiosis in the whole spectrum of nature from termites to men. Mitochondria, he explains, "replicate in their own fashion, privately, with their own DNA and RNA quite different from ours." They are "stable and responsible lodgers" in the human body. Symbiosis is a symbol don, November 1975.) $\$ 6.95$; $£ 3.50$. correct; this is an extraordinary book. say that he looks with wonder and of the interdependence of living things, part of the process which constructed metazoans from single cells, communities from metazoans, and ecosystems from communities. He calls as witness the symbiotic service which the protozoan Myxotricha paradoxa gives to the termite community, providing the enzyme to break down cellulose.

Another theme of these essays starts with the question asked two generations ago by W. M. Wheeler: "To what extent can insect communities be regarded as organisms?" (It was Hegel who asked a homologous question about the State.) A familiar enough idea, but Dr Thomas illuminates it from a fresh direction:

\begin{abstract}
"Viewed from a suitable height, the aggregating clusters of medical scientists in the bright sunlight ... at Atlantic City, swarmed there from everywhere for the annual meetings, have the look of assemblages of social insects. There is the same vibrating, ionic movement the darting back and forth of jerky individuals to touch antennae and exchange small bits of information...
\end{abstract}

And what are the scientists doing? They "are linked in circuits for the storage, processing, and retrieval of information." What societies of termites do with cellulose, societies of men do with information, rearranging it against randomness into such patterns as quantum mechanics, immunology, genetics. And so Dr Thomas sees an analogy between the termite team (ineffective unless there is a quorum of termites), building something beyond the conception of any of the individual builders, and the invisible college of scientists, piecing together fragments of information into ordered patterns of understanding. There even seems to a similar compulsion:

"Scientists at work have the look of creatures following genetic instructions; they seem to be under the influence of a deeply placed human instinct. They rather like young animals engaged in savage play."

As a solution appears they become agitated, as bees do in a disturbed hive, and there "suddenly emerges, with the purity of a slow phrase of music, a single new piece of truth about nature."

Fanciful? Yes, it is; but it is this sort of fancy which acts as a catalyst for hard science. As A. N. Whitehead wrote: "It is more important that a proposition be interesting than that it be true." And Dr Thomas' theme is intensely interesting, for he goes on to suggest that there is one activity of human communities which has an uncanny resemblance to the genetically coded activities of social insects, namely the development and evolution of language. Chomsky has postulated that language must be a biological property of the human mind. The capacity to apprehend syntax is genetically coded. Language grows, changes, evolves, independently of any control or planning by individuals or committees or governments. All of us unconsciously and inevitably contribute to its growth and metamorphosis, with as little understanding of how we do it as a termite has of the architecture of its hill. Language, Dr Thomas says, is "the most compulsively collective, genetically programmed, species-specific, and are, despite their efforts at dignity, autonomic of all the things we do, and

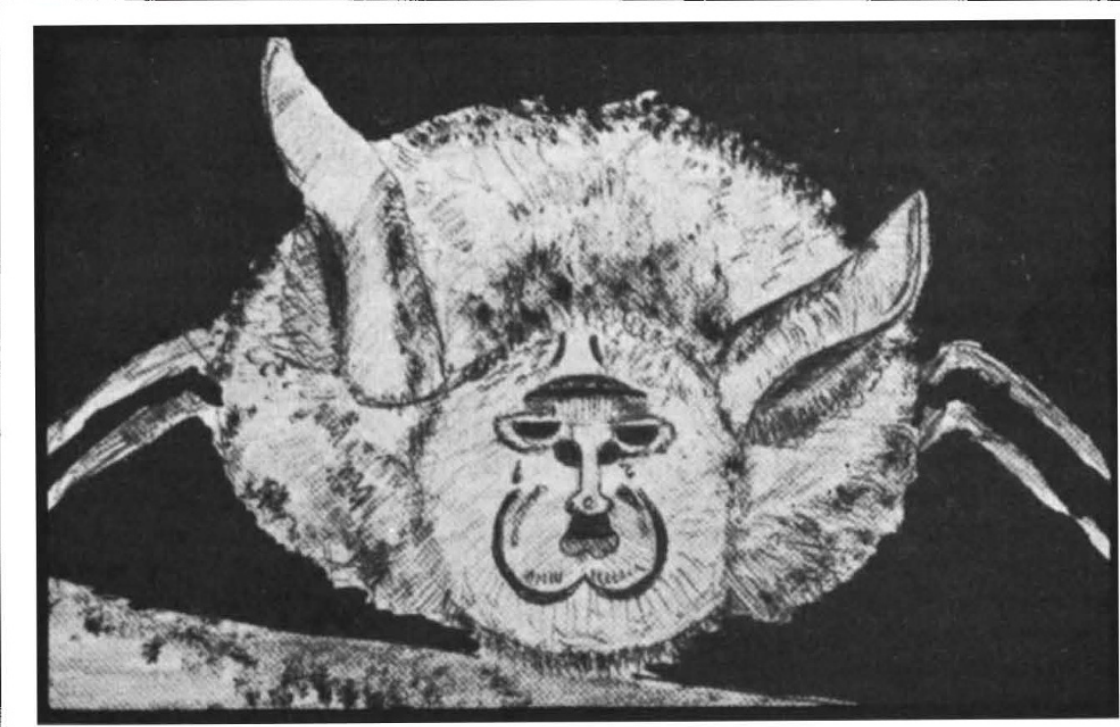

Greater Horshoe Bat with minute eyes on either side of the nose. The curved portion below the nose and surrounding it represents the nose-ieaf, which directs sound waves emitted through the nose during flight. Taken from Vision in the Animal World by R. H. Smythe. (Macmillan: London and Basingstoke, 1975.) £6.95. 